Original

\title{
Levels of Dioxins in Japanese Fruit in 1999 to 2002 and Estimation of Their Intake
}

(Received April 6, 2005)

\author{
Nobuyasu SeIkE ${ }^{\dagger}$, Tetsuhisa Miwa, Takashi Otani and Masako UejI \\ (National Institute for Agro-Environmental Sciences: 3-1-3, Kannondai, Tsukuba, \\ Ibaraki 305-8604, Japan; ${ }^{\dagger}$ Corresponding author)
}

\begin{abstract}
A total of 148 samples of nine species of fruit were collected between 1999 and 2002 and analyzed for PCDDs, PCDFs (PCDD/Fs) and Coplanar PCBs. Sampling points within about $1 \mathrm{~km}$ of operational municipal waste incinerators that were considered sources of dioxins were defined as "near-source" areas, and all other sampling points were defined as "general" areas. The TEQ of apples collected from near-source areas was significantly higher than that from general areas $(p<$ 0.05). 3,3',4,4',5-PeCB (\#126) was the main contributor to this difference in TEQs between apples collected from near-source areas and from general area. A principal component analysis performed to estimate the source of this congener revealed that not only the municipal waste incinerators, but also PCBs in the environment were associated with the high TEQ in apples collected from near-source areas. The daily intakes of PCDD/Fs and Coplanar PCBs from the fruits including skin were estimated to be $0.0082 \mathrm{pg}$-TEQ/kg b.w./day $(\mathrm{ND}=0)$ and $0.072 \mathrm{pg}$-TEQ/ $\mathrm{kg}$ b.w./day $(\mathrm{ND}=1 / 2 \mathrm{LOQ})$. Though these values are likely to be overestimates, they are far lower than the tolerable daily intake set in Japan for PCDD/Fs and Coplanar PCBs (4 pg-TEQ/kg b.w./day). It is thought that fruit intake is not an important pathway of human exposure to $\mathrm{PCDD} / \mathrm{Fs}$ and Coplanar PCBs.
\end{abstract}

Key words: polychlorinated dibenzo-p-dioxins; polychlorinated dibenzofurans; Coplanar PCBs; fruits; daily intake

\section{Introduction}

Polychlorinated dibenzo- $p$-dioxins and dibenzofurans (PCDD/Fs) and Coplanar polychlorinated biphenyls (Coplanar PCBs) are widely spread environmental pollutants. PCDD/Fs and Coplanar PCBs express toxicities related to carcinogenicity, teratogenicity, immune system impairment and other adverse effects. They are very slightly soluble in water and decompose slowly in the environment. Processes of combustion and incineration in municipal waste incinerators ${ }^{1)}$; Kanechlors $^{2)}$; and impurities in organochlorine products such as pentachlorophenol (PCP) ${ }^{3)-5)}$ and 1,3,5-trichloro-2-(4nitrophenoxy)benzene (chloronitrofen, $\mathrm{CNP})^{4)-6}$ ) are well known as sources of PCDD/Fs and Coplanar PCBs.

The Law Concerning Special Measures against Dioxins (The Dioxins Law) was enacted in 1999 and came into force in 2000. This law prescribes effluent control, the tolerable daily intake (TDI), and the values of environmental standards for PCDD/Fs and Coplanar PCBs in the atmosphere, water, sediments and soils. In this context, from 1999 to 2002 the Ministry of Agriculture, Forestry and Fisheries conducted a survey to review the status of $\mathrm{PCDD} / \mathrm{F}$ and Coplanar $\mathrm{PCB}$ contamination of agricultural crops and soils. Here, we analyzed the results of the survey of PCDD/Fs and Coplanar PCBs in fruits and fruit-growing soils in order to 1) elucidate the uptake pathway in fruit, 2) evaluate the influence of municipal waste incinerators on contamination of fruit, and 3) estimate the daily human intake of these contaminants from fruits.

\section{Materials and Methods}

\section{Samples}

Samples of a total of nine species of fruit $(n=87)$, i.e., apples, chestnuts, grapes, Japanese apricots, mandarin oranges, peaches, pears, persimmons, and pon-kan oranges, as well as soils $(n=87)$ where the fruits were grown, were collected between 1999 and 2002. In addition, from 2000 to 2002 , fruit samples $(n=61)$ were collected in areas where soils samples were not collected. Sampling points within about $1 \mathrm{~km}$ of operational municipal waste incinerators that were considered sources of dioxins were defined as "near-source" areas, and all other sampling points were defined as "general" areas. The distance between the sampling point and the nearest operational municipal waste incinerator was calculated based on Global Positioning System (GPS) data. The numbers of samples collected from nearsource and general areas are shown by sampling year in Tables 1 and 2 .

Sample preparation procedures are described in detail elsewhere ${ }^{7}$. In brief, for collected samples of apples, grapes, Japanese apricot, pears, and persimmons, the 
Table 1. Number of Fruit Samples Collected between 1999 and 2002

\begin{tabular}{|c|c|c|c|c|c|c|c|c|c|c|}
\hline \multirow{2}{*}{ Year } & \multicolumn{2}{|c|}{1999} & \multicolumn{2}{|c|}{2000} & \multicolumn{2}{|c|}{2001} & \multicolumn{2}{|c|}{2002} & \multicolumn{2}{|c|}{ Total } \\
\hline & Source*1 & General*2 & Source*1 & General $^{* 2}$ & Source*1 & General*2 & Source*1 & General*2 & Source*1 & General $^{* 2}$ \\
\hline Apple & 1 & 3 & 0 & 4 & 0 & 2 & 4 & 8 & 5 & 17 \\
\hline Chestnut & 2 & 0 & 0 & 0 & 0 & 2 & 0 & 0 & 2 & 2 \\
\hline Grape & 2 & 4 & $4(2)^{* 3}$ & $6(2)^{* 3}$ & 2 & 4 & 0 & 4 & $8(2)^{* 3}$ & $18(2)^{* 3}$ \\
\hline Japanese apricot & 0 & 0 & 2 & 0 & 0 & 0 & 2 & 0 & 4 & 0 \\
\hline Mandarin orange & 2 & 4 & 4 & 18 & 0 & 2 & 2 & 2 & 8 & 26 \\
\hline Peach & 0 & 0 & 2 & 4 & 0 & 2 & 0 & 0 & 2 & 6 \\
\hline Pear & 0 & 0 & $2(2)^{* 3}$ & 4 & 0 & 0 & $8(2)^{* 3}$ & $8(1)^{* 3}$ & $10(4)^{* 3}$ & $12(1)^{* 3}$ \\
\hline Persimmon & 4 & 0 & 6 & 10 & 0 & 4 & 0 & 0 & 10 & 14 \\
\hline Pon-kan orange & 0 & 0 & 0 & 2 & 0 & 0 & 0 & 2 & 0 & 4 \\
\hline
\end{tabular}

*1 Sampling points located within about $1 \mathrm{~km}$ of operational municipal waste incinerators

*2 Sampling points more than $1 \mathrm{~km}$ from operational municipal waste incinerators

*3 Number of samples grown in greenhouses or plastic tunnels

Table 2. Number of Soil Samples Collected between 1999 and 2002

\begin{tabular}{|c|c|c|c|c|c|c|c|c|c|c|}
\hline \multirow{2}{*}{ Year } & \multicolumn{2}{|c|}{1999} & \multicolumn{2}{|c|}{2000} & \multicolumn{2}{|c|}{2001} & \multicolumn{2}{|c|}{2002} & \multicolumn{2}{|c|}{ Total } \\
\hline & Source*1 & General*2 $^{* 2}$ & Source*1 & General $^{* 2}$ & Source*1 & General$^{* 2}$ & Source*1 & General*2 & Source*1 & General*2 $^{* 2}$ \\
\hline Apple & 1 & 3 & 0 & 2 & 0 & 1 & 2 & 4 & 3 & 10 \\
\hline Chestnut & 2 & 0 & 0 & 0 & 0 & 1 & 0 & 0 & 2 & 1 \\
\hline Grape & 2 & 4 & $2(1)^{* 3}$ & $3(1)^{* 3}$ & 1 & 2 & 0 & 2 & $5(1)^{* 3}$ & $11(1)^{* 3}$ \\
\hline Japanese apricot & 0 & 0 & 1 & 0 & 0 & 0 & 1 & 0 & 2 & 0 \\
\hline Mandarin orange & 2 & 4 & 2 & 9 & 0 & 1 & 1 & 1 & 5 & 15 \\
\hline Peach & 0 & 0 & 1 & 2 & 0 & 1 & 0 & 0 & 1 & 3 \\
\hline Pear & 0 & 0 & $1(1)^{* 3}$ & 2 & 0 & 0 & $5(2)^{* 3}$ & $5(1)^{* 3}$ & $6(3)^{* 3}$ & $7(1)^{* 3}$ \\
\hline Persimmon & 4 & 0 & 3 & 5 & 0 & 2 & 0 & 0 & 7 & 7 \\
\hline Pon-kan orange & 0 & 0 & 0 & 1 & 0 & 0 & 0 & 1 & 0 & 2 \\
\hline
\end{tabular}

*1 Sampling points located within about $1 \mathrm{~km}$ of operational municipal waste incinerators

*2 Sampling points more than $1 \mathrm{~km}$ from operational municipal waste incinerators

*3 Number of samples collected from greenhouses or plastic tunnels

peduncles, cores, and seeds were removed and the fructifications, with skin, were homogenized in a mixer. For pon-kan oranges, the whole fructifications were homogenized in a mixer. For chestnuts, mandarin oranges, and peaches, the skin and seeds were removed and the fructifications were homogenized in a mixer. Soil samples sifted through a mesh screen (mesh openings: less than $2 \mathrm{~mm}$ ) after air-drying were used for analysis. These samples were preserved in a freezer at $-20^{\circ} \mathrm{C}$ until extraction.

\section{Analysis}

Analytical methods of fruits and soils are described in detail elsewhere ${ }^{8), 9)}$. In brief, fruit samples (approximately 100 g) were weighed and $17{ }^{13} \mathrm{C}_{12}$-labeled 2,3,7,8chlorine-substituted $\mathrm{PCDD} / \mathrm{Fs}$, four ${ }^{13} \mathrm{C}_{12}$-labeled nonortho-PCBs, and eight ${ }^{13} \mathrm{C}_{12}$-labeled mono-ortho-PCBs were added to each sample as internal standards. The fruit samples were then extracted under continuous shaking three times with acetone- $n$-hexane $(1: 1, \mathrm{v} / \mathrm{v})$. Soil samples (approximately $10 \mathrm{~g}$ ) were extracted with toluene for $16 \mathrm{hr}$ in a Soxhlet apparatus, and then 17 ${ }^{13} \mathrm{C}_{12}$-labeled 2,3,7,8-chlorine-substituted PCDD/Fs, four ${ }^{13} \mathrm{C}_{12}$-labeled non-ortho-PCBs, and eight ${ }^{13} \mathrm{C}_{12}$-labeled mono-ortho-PCBs were added to each sample as internal standards. Sample solutions of fruit and soil after ex- traction were applied to a multi-layer silica gel column (silver nitrate-impregnated silica gel, sulfuric acidimpregnated silica gel, and $\mathrm{KOH}$-impregnated silica gel) and were eluted with $n$-hexane. The solutions after concentration were applied to an alumina column and mono-ortho-PCBs were eluted with dichloromethane$n$-hexane $(2: 98, \mathrm{v} / \mathrm{v})$. Then PCDD/Fs and non-orthoPCBs were eluted with a mixture of dichloromethane$n$-hexane $(60: 40, \mathrm{v} / \mathrm{v})$. The latter fractions were concentrated and applied to an activated carbon column. The first fraction eluted with dichloromethane- $n$ hexane $(25: 75, \mathrm{v} / \mathrm{v})$ was discarded. The second fraction eluted with toluene contained PCDD/Fs and nonortho-PCBs. ${ }^{13} \mathrm{C}_{12}$-labeled $2,3^{\prime}, 4^{\prime}, 5$-TeCB (\#70), 2,3,3',5,5' $\mathrm{PeCB}(\# 111)$ and $2,2^{\prime}, 3,4,4^{\prime}, 5^{\prime}-\mathrm{HxCB}$ (\#138) were added to the mono-ortho-PCBs fraction. Two ${ }^{13} \mathrm{C}_{12}$-labeled PCDFs (1,2,3,4,6-PeCDF and 1,2,3,4,6,8,9-HpCDF) with the above labeled PCBs congeners were added to the $\mathrm{PCDD} / \mathrm{Fs}$ and non-ortho-PCBs eluted fraction as recovery standards.

Measurement of PCDD/Fs and Coplanar PCBs was performed with a high-resolution gas chromatograph equipped with a high-resolution mass spectrometer (HRGC/HRMS; HP6890/AutoSpec-Ultima Micromass). SP2331 $(60 \mathrm{~m} \times 0.25 \mathrm{~mm}$ i.d. $\times 0.20 \mu \mathrm{m}$ film thickness, SUPELCO $)$ and DB-17 $(30 \mathrm{~m} \times 0.32 \mathrm{~mm}$ i.d. $\times 0.25 \mu \mathrm{m}$ 
Table 3. Limits of Quantitation (LOQs) in Fruit Samples Collected between 1999 and 2002

\begin{tabular}{|c|c|}
\hline & LOQ (pg/g wet weight) \\
\hline \multicolumn{2}{|l|}{$\mathrm{PCDD} / \mathrm{Fs}$} \\
\hline TeCDDs & 0.01 \\
\hline PeCDDs & 0.01 \\
\hline HxCDDs & 0.02 \\
\hline HpCDDs & 0.02 \\
\hline OCDD & 0.05 \\
\hline TeCDFs & 0.01 \\
\hline PeCDFs & 0.01 \\
\hline $\mathrm{HxCDFs}$ & 0.02 \\
\hline HpCDFs & 0.02 \\
\hline $\mathrm{OCDF}$ & 0.05 \\
\hline \multicolumn{2}{|l|}{ Coplanar PCBs } \\
\hline \multicolumn{2}{|l|}{ Non-ortho-PCBs } \\
\hline $3,4,4^{\prime}, 5-\mathrm{TeCB}(\# 81)$ & 0.1 \\
\hline $3,3^{\prime}, 4,4^{\prime}-\mathrm{TeCB}(\# 77)$ & 0.1 \\
\hline $3,3^{\prime}, 4,4^{\prime}, 5-\mathrm{PeCB}(\# 126)$ & 0.1 \\
\hline $3,3^{\prime}, 4,4^{\prime}, 5,5^{\prime}-\mathrm{HxCB}(\# 169)$ & 0.1 \\
\hline \multicolumn{2}{|l|}{ Mono-ortho-PCBs } \\
\hline $2^{\prime}, 3,4,4^{\prime}, 5-\mathrm{PeCB}(\# 123)$ & 1 \\
\hline $2,3^{\prime}, 4,4^{\prime}, 5-\mathrm{PeCB}(\# 118)$ & 1 \\
\hline $2,3,3^{\prime}, 4,4^{\prime}-\mathrm{PeCB}(\# 105)$ & 1 \\
\hline $2,3,4,4^{\prime}, 5-\mathrm{PeCB}(\# 114)$ & 1 \\
\hline $2,3^{\prime}, 4,4^{\prime}, 5,5^{\prime}-\mathrm{HxCB}(\# 167)$ & 1 \\
\hline $2,3,3^{\prime}, 4,4^{\prime}, 5-\mathrm{HxCB}(\# 156)$ & 1 \\
\hline $2,3,3^{\prime}, 4,4^{\prime}, 5^{\prime}-\mathrm{HxCB}(\# 157)$ & 1 \\
\hline $2,3,3^{\prime}, 4,4^{\prime}, 5,5^{\prime}-\mathrm{HpCB}(\# 189)$ & 1 \\
\hline
\end{tabular}

film thickness, J\&W Scientific) were used for measurement of PCDD/Fs, and HT-8 (50 m $\times 0.22 \mathrm{~mm}$ i.d. $\times 0.25$ $\mu \mathrm{m}$ film thickness, SGE) was used for Coplanar PCBs. Limits of quantitation (LOQs) for each congener of PCDD/Fs and Coplanar PCBs are shown in Table 3. The LOQs were calculated based on the Provisional guidelines for analysis of polychlorinated dibenzo-pdioxins, dibenzofurans and coplanar PCBs in foods ${ }^{8)}$. Recovery rates of ${ }^{13} \mathrm{C}_{12}$-labeled $\mathrm{PCDD} / \mathrm{Fs}$ and Coplanar $\mathrm{PCBs}$ added before extraction ranged from $40 \%$ to $120 \%$. If the values obtained were beyond this range, the sample was reanalyzed by repeating the processes used after extraction.
Statistical analysis

Statistical analysis (one-way analysis of variance, the least significant difference method, $t$-test, Welch's test, and principal component analysis) were performed by Excel Statistics 2002 for Windows (Social Survey Research Information Co., Ltd.; SSRI).

\section{Results and Discussion}

Levels and uptake pathways of $P C D D / F$ s and Coplanar $P C B s$ in fruit

WHO-toxicity equivalent factors ${ }^{10)}$ were used to calculate the TEQs of PCDD/Fs and Coplanar PCBs in fruit samples. The mean TEQs in the nine species of fruit ranged from 0 to $0.033 \mathrm{pg}$-TEQ/g wet weight and were extremely low (Table 4).

Two pathways of uptake of PCDD/Fs and Coplanar PCBs by agricultural crops can be considered: 1) absorption of PCDD/Fs and Coplanar PCBs present in the soil from the roots; and 2) adsorption and adhesion of $\mathrm{PCDD} / \mathrm{Fs}$ and Coplanar PCBs present in the atmosphere onto the surface of the plant. With regard to absorption from the soil, it has been pointed out that only crops of the cucumber family (Cucurbitaceae), such as zucchini, can absorb from the roots ${ }^{11-13)}$. In most crops, the uptake of $\mathrm{PCDD} / \mathrm{Fs}$ and Coplanar PCBs is thought to occur by adsorption and adhesion of congeners present in the atmosphere to the surface of the plant ${ }^{14)-17)}$.

To estimate the uptake pathways of $\mathrm{PCDD} / \mathrm{Fs}$ and Coplanar PCBs, the relationship between the TEQs in the fruits and the soils where the fruits were grown was examined (Fig. 1). No significant correlation was observed between the TEQs in the fruits analyzed in this study (chestnuts, peach and pon-kan oranges were excluded because the numbers of fruits with corresponding soil samples were small) and the TEQs of the soils. It is considered that the main uptake pathways of $\mathrm{PCDD} / \mathrm{Fs}$ and Coplanar PCBs in fruits is not absorption via the roots, but adsorption and adhesion of $\mathrm{PCDD} / \mathrm{Fs}$ and Coplanar PCBs present in the atmosphere on to the surface of the plant.

The TEQs were compared among the nine species of fruit, using multiple comparisons by one-way analysis of variance and the least significant difference method (Fig. 2). First of all, one-way analysis of variance was

Table 4. TEQ Levels (mean \pm S.D.) of PCDD/Fs and Coplanar PCBs (pg-TEQ/g wet weight) in Fruit Samples Collected between 1999 and 2002 in Japan

\begin{tabular}{|c|c|c|c|}
\hline & \multicolumn{3}{|c|}{ TEQ } \\
\hline & $\mathrm{PCDD} / \mathrm{Fs}$ & Coplanar PCBs & Total \\
\hline Apple & $0.00025 \pm 0.00054$ & $0.0017 \pm 0.0040$ & $0.0019 \pm 0.0040$ \\
\hline Chestnut & $0.0000015 \pm 0.0000026$ & $0.000013 \pm 0.000026$ & $0.000014 \pm 0.000021$ \\
\hline Grape & $0.029 \pm 0.067$ & $0.0043 \pm 0.000077$ & $0.033 \pm 0.080$ \\
\hline Japanese apricot & $0.00011 \pm 0.00010$ & $0.00016 \pm 0.000040$ & $0.00026 \pm 0.000065$ \\
\hline Mandarin orange & $0.0000019 \pm 0.0000075$ & $0.0000023 \pm 0.0000077$ & $0.0000041 \pm 0.000010$ \\
\hline Peach & $0.0000029 \pm 0.0000041$ & $0.000048 \pm 0.0006$ & $0.000050 \pm 0.000081$ \\
\hline Pear & $0.000068 \pm 0.00014$ & $0.0000091 \pm 0.000021$ & $0.000078 \pm 0.00015$ \\
\hline Persimmon & $0.0039 \pm 0.014$ & $0.0010 \pm 0.0029$ & $0.0049 \pm 0.016$ \\
\hline Pon-kan orange & ND & ND & ND \\
\hline
\end{tabular}




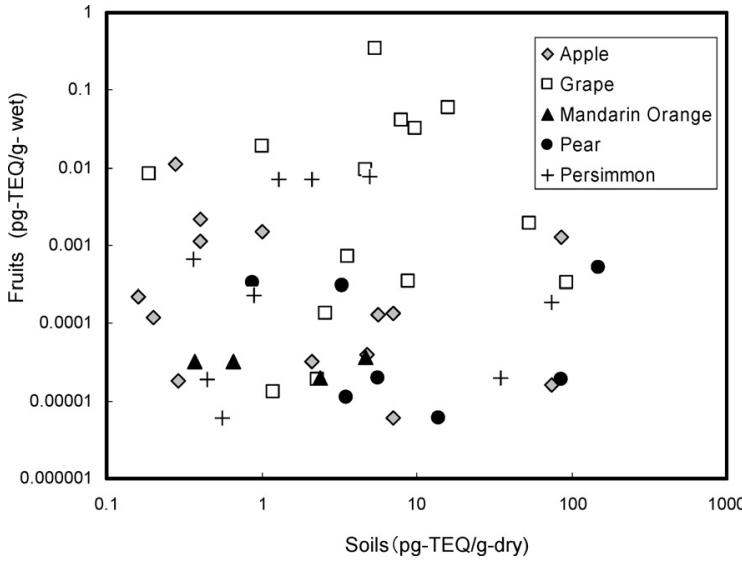

Fig. 1. Relationships between TEQs in fruits and soils Correlation coefficients $(r)$ are -0.11 (apple), -0.15 (grape), -0.14 (mandarin orange), 0.48 (pear), and -0.23 (persimmon).

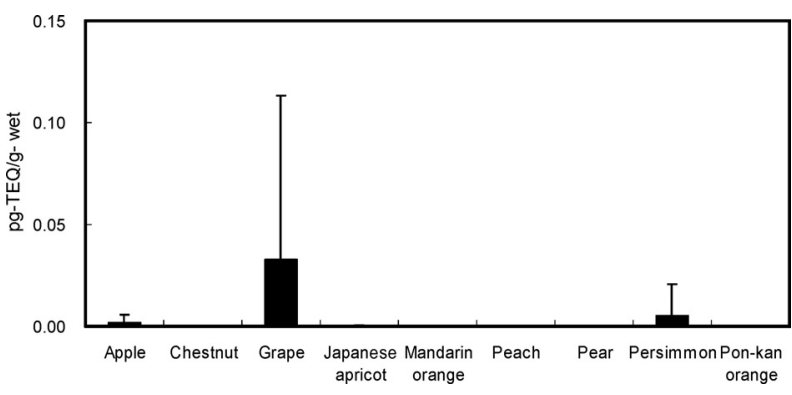

Fig. 2. Comparison of mean TEQs in fruits with and without skins

Bars denote standard deviations.

performed, revealing that the TEQs of the nine species of fruit were significantly different $(p<0.05)$. Next, when multiple comparisons by the least significant difference method (level of significance: 0.05) were performed, it was determined that only grapes had significantly higher TEQs than the other fruits $(p<$ 0.01). This is reasonable, because grapes have the largest skin area per unit weight among the nine species of fruit.

Comparison of TEQs in fruits collected from near-source and general areas

The influence of $\mathrm{PCDD} / \mathrm{Fs}$ and Coplanar PCBs emitted from municipal waste incinerators on TEQs in fruit was examined. TEQs were compared between the two types of sampling area. The data used were the TEQs in apples, grapes, pears, and persimmons, for which many samples had been collected. To compare the data between near-source and general areas, after the test of homogeneity of variance had been conducted, Welch's test was applied when the assumption of homoscedasticity was violated (apples, pears, and persimmons) and the $t$-test was applied when the assumption of homoscedasticity was not violated (grapes). Figure 3 shows that no significant differences were observed in the TEQs in grapes, pears, and persimmons between near-source and general areas, although

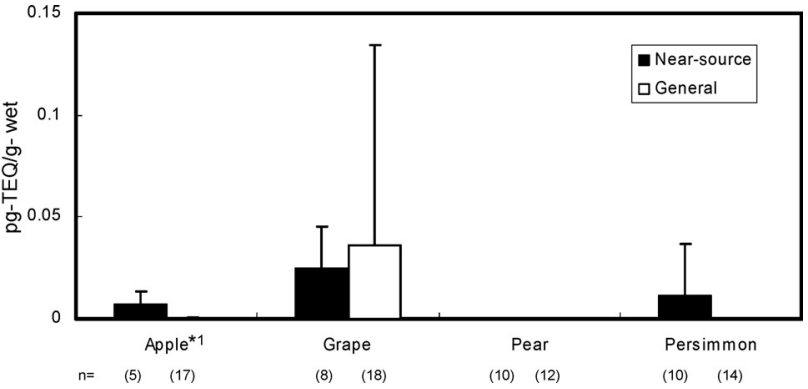

Fig. 3. Comparison of mean TEQs in fruits collected from near-source and general areas Bars denote standard deviations.

*1 TEQs in apples from near-source areas were significantly $(p<0.05)$ higher by Welch's test.

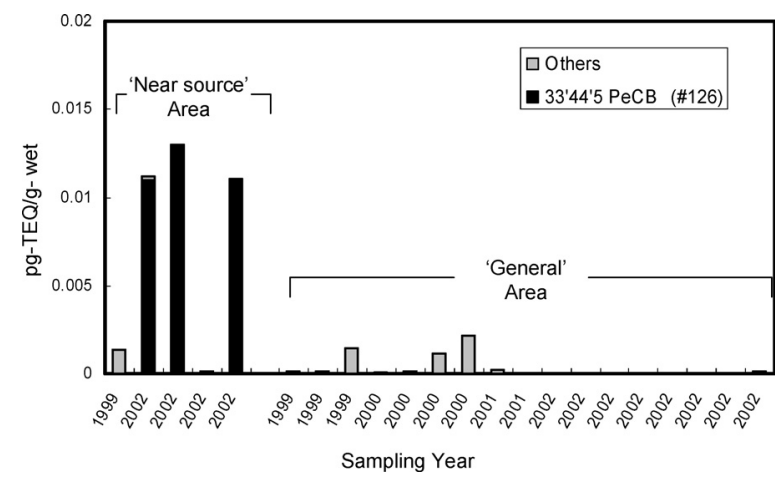

Fig. 4. The TEQs contributed by $3,3^{\prime}, 4,4^{\prime}, 5-\mathrm{PeCB}(\# 126)$ and other congeners in apples collected from near-source and general areas between 1999 and 2002

the TEQ in apples in near-source areas was significantly higher than that in general areas $(p<0.05)$. The main contributor for TEQ calculation in apples collected from near-source and general areas between 1999 and 2002 is shown in Fig. 4. It was found that the TEQs in three apples in near-source areas in 2002 were higher than those in general areas, and that $3,3^{\prime}, 4,4^{\prime}, 5-\mathrm{PeCB}$ (\#126) was the main contributor in the three apples. With regard to the presence of $3,3^{\prime}, 4,4^{\prime}, 5$-PeCB (\#126) in the atmosphere, not only emissions from combustion and incineration facilities (such as waste gases from municipal waste incinerators), but also volatilization from environmental pollutants (such as wastes containing Kanechlors used previously) have been widely identified as sources ${ }^{18)}$.

Therefore, a principal component analysis (PCA) was performed in order to estimate the source of $3,3^{\prime}, 4,4^{\prime}, 5$ PeCB (\#126) in apples. In general, concentrations or relative concentrations of congeners are used as variables for PCA to estimate the source. In this study, the data used were relative concentrations of five congeners - 2,3,3' ${ }^{\prime}, 4,4^{\prime}$-PeCB (\#105), 2,3,4,4', 5 -PeCB (\#114), 2,3',

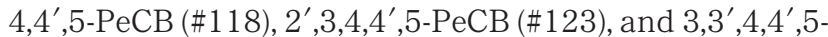
PeCB (\#126) - in apple collected from near-source and general areas in 2001 and 2002; in Kanechlors (KC-300, $400,500,600)^{19)}$; and in emission gases from municipal waste incinerators in Japan ${ }^{20)}$. 




Fig. 5. Plot of principal component scores of apples collected from near-source and general areas in 2001 and 2002 , Kanechlors, and emission gases from municipal waste incinerators

- apples collected from near-source areas, $(\bigcirc)$ apples collected from general areas, $(\times)$ Kanechlors,

emission gases from municipal waste incinerators.

Bar graphs show the PeCB compositions.

Figure 5 is a plot of principal component scores and the average compositions of the five congeners in Kanechlors, in the gases emitted from municipal waste incinerators, and in the apples collected from nearsource and general areas. The contributions of principal component 1 (PC1) and principal component 2 (PC2) were $68 \%$ and $23 \%$, respectively; thus PC1 could explain most of the variation. With regard to the factor loadings of $\mathrm{PC} 1$, factor loadings for $2,3,3^{\prime}, 4,4^{\prime}-\mathrm{PeCB}$ (\#105) and 2,3',4,4',5-PeCB (\#118) were high, whereas that for $3,3^{\prime}, 4,4^{\prime}, 5$-PeCB (\#126) was low. In addition, according to the PCA plot shown in Fig. 5, it was considered that PC1 was a source of PCBs; it consists of Kanechlors and the gases emitted from municipal waste incinerators. The contribution of PC2 was unclear.

\section{Daily intakes of $P C D D / F$ s and Coplanar PCBs}

Daily intakes of PCDD/Fs and Coplanar PCBs from fruits were estimated (Table 5). The daily intakes of PCDD/Fs and Coplanar PCBs from each fruit were obtained for both $\mathrm{ND}=0$ and $\mathrm{ND}=1 / 2 \mathrm{LOQ}$, by means of the following procedure. The TEQs of the fruits in Table 4 were multiplied by the daily intakes of individual fruits ${ }^{21-23)}$, and the values were divided by an arbitrary body weight $(50 \mathrm{~kg})$. Some fruits (apples, grapes, Japanese apricot, pears, persimmons, and pon-kan) were analyzed with their skin, so the daily intakes of PCDD/ Fs and Coplanar PCBs would have been overestimated in this study. The daily intakes of PCDD/Fs and Coplanar PCBs from the fruits were estimated to be $0.0082 \mathrm{pg}-\mathrm{TEQ} / \mathrm{kg}$ b.w./day $(\mathrm{ND}=0)$ and $0.072 \mathrm{pg}$ -

Table 5. Estimated Daily Intakes (mean \pm S.D., pg-TEQ/kg b.w./day) from Fruits in Japan

\begin{tabular}{lccc}
\hline \hline & $\begin{array}{c}\text { Intake of fruit } \\
(\mathrm{g} / \text { day })^{* 1}\end{array}$ & $\begin{array}{c}\text { TEQ } \\
(\mathrm{ND}=0)\end{array}$ & $\begin{array}{c}\text { TEQ } \\
(\mathrm{ND}=1 / 2 \mathrm{LOQ})\end{array}$ \\
\hline Apple & 35.3 & $0.0014 \pm 0.0029$ & $0.020 \pm 0.0017$ \\
Chestnut & 0.7 & $0.0000002 \pm 0.00000034$ & $0.00038 \pm 0.00000031$ \\
Grape & 5.8 & $0.0038 \pm 0.0095$ & $0.0064 \pm 0.0088$ \\
Japanese apricot & 1.1 & $0.0000058 \pm 0.0000016$ & $0.00060 \pm 0.00000039$ \\
Mandarin orange & 41.6 & $0.0000035 \pm 0.0000087$ & $0.022 \pm 0.0000076$ \\
Peach & 0.5 & $0.00000051 \pm 0.00000086$ & $0.00027 \pm 0.00000060$ \\
Pear & 5.1 & $0.0000079 \pm 0.000015$ & $0.0028 \pm 0.000011$ \\
Persimmon & 31.4 & $0.0031 \pm 0.011$ & $0.019 \pm 0.0079$ \\
Pon-kan orange & 0.4 & 0 & $0.00022 \pm 0$ \\
Total & & $0.0082 \pm 0.014$ & $0.072 \pm 0.012$ \\
\hline
\end{tabular}

*1 Intake of fruits was obtained from National Nutrition Survey in 1998, 1999 and 2000.

Some fruits (apples, grapes, Japanese apricot, pears, persimmons and pon-kan) were analyzed with skin, so the daily intakes of PCDD/Fs and Coplanar PCBs would be overestimated in these cases. 
TEQ/kg b.w./day (ND=1/2 LOQ). These values are far lower than the tolerable daily intake set in Japan for PCDD/Fs and Coplanar PCBs (4 pg-TEQ/kg b.w./day). Tsutsumi et al. ${ }^{24)}$ conducted a total diet study to calculate daily intakes of PCDD/Fs and Coplanar PCBs from food, and reported that in 1999 and 2000 they were 2.25 pg-TEQ/kg b.w./day $(\mathrm{ND}=0)$ and $3.22 \mathrm{pg}-\mathrm{TEQ} / \mathrm{kg}$ b. w./day (ND = 1/2 LOD). Thus, the daily intakes of TEQ $(\mathrm{ND}=0)$ of $\mathrm{PCDD} / \mathrm{Fs}$ and Coplanar PCBs originating from fruits are extremely low (maximum of approximately $3 \%$ ) as a proportion of the intakes from all foodstuffs. Daily intakes of PCDD/Fs and Coplanar PCBs from fruits were $0.06 \mathrm{pg}-\mathrm{TEQ} / \mathrm{kg}$ b.w./day in $\mathrm{UK}^{25)}, 0.04$ pg-TEQ/kg b.w./day in Germany ${ }^{26)}$, and undetectable in the $\mathrm{US}^{27)}$. The reported data for other countries are similar to the findings of this study. The proportions of the intakes of $\mathrm{PCDD} / \mathrm{Fs}$ and Coplanar PCBs from fruits with respect to all foodstuffs were $2.5 \%$ in UK and 3.3\% in Germany, respectively. It seems that contamination of $\mathrm{PCDD} / \mathrm{Fs}$ and Coplanar PCBs in fruits in Japan is comparable with that in other countries.

Temporal changes (1977-2000) of the daily intake of $\mathrm{PCDD} / \mathrm{Fs}$ and Coplanar PCBs originating from food in Japan were reported by Toyoda et $a l^{28)}$ and Tsutsumi et $a l^{24)}$. Total intakes of PCDD/Fs and Coplanar PCBs decreased from $8.18 \mathrm{pg}-\mathrm{TEQ} / \mathrm{kg}$ b.w./day $(\mathrm{ND}=0)$ in 1977 to $2.25 \mathrm{pg}-\mathrm{TEQ} / \mathrm{kg}$ b.w./day $(\mathrm{ND}=0)$ in 1999/ 2000. However, the daily intake of PCDD/Fs and Coplanar PCBs originating from fruits in 1977 and $1999 / 2000$ in Japan were 0.0046, and 0.0038 pg-TEQ/ $\mathrm{kg}$ b.w./day $(\mathrm{ND}=0)$, respectively. The major contributors to total intake of PCDD/Fs and Coplanar PCBs in the food category were fish, shellfish, meat, eggs and daily products, whereas rice, vegetables and fruits were minor contributors ${ }^{24), 28)}$. It is therefore thought that consumption of agricultural crops, particularly fruits, is not an important pathway of human exposure to PCDD/Fs and Coplanar PCBs.

\section{Acknowledgment}

We thank Mr. Segawa (Ministry of Agriculture, Forestry and Fisheries in Japan) for helpful discussions.

\section{References}

1) Hiraoka, M., Okajima, S., Source control technologies in MSW incineration plants. Organohalogen Comd., 19, 275-291 (1994).

2) Wakimoto, T., Kannan, N., Ono, M., Tatsukawa, R., Masuda, Y., Isomer-specific determination of polychlorinated dibenzofurans in Japanese and American polychlorinated biphenyls. Chemosphere, 17, 743-750 (1988).

3) Hagenmaier, H., Brunner, H., Isomer specific analysis of pentachlorophenol and sodium pentachlorophenate for 2,3,7,8-substituted PCDD and PCDF at sub-ppb levels. Chemosphere, 16, 1,759-1,764 (1987).

4) Masunaga, S., Takasuga, T., Nakanishi, J., Dioxin and dioxin-like PCB impurities in some Japanese agrochemical formulations. Chemosphere, 44, 873-885 (2001).
5) Seike, N., Otani, T., Ueji, M., Takasuga, T., Tsuzuki, T., Temporal change of polychlorinated dibenzo-p-dioxins, dibenzofurans and dioxin like polychlorinated biphenyls source in paddy soils. Kankyou Kagaku (J. Environ. Chem.), 13, 117-131 (2003).

6) Yamagishi, T., Miyazaki, T., Akiyama, K., Morita, M., Nakagawa, J., Hori, S., Kaneko, S., Polychlorinated dibenzo-p-dioxins and dibenzofurans in commercial diphenyl ester herbicides, and in freshwater fish collected from the application area. Chemosphere, 10, 1,137-1,144 (1981).

7) Nouyaku No Sakumotsu Zanryu Shiken Zissi Youryou (Execution points for pesticides residue in crops) (Apr., 1973), Ministry of Agriculture, Forestry and Fisheries.

8) Shokuhinchu No Daiokishinrui Oyobi Kopurana PCB No Sokuteihouhou Zantei Gaidorain (Provisional guidelines for analysis of polychlorinated dibenzo- $p$-dioxins, dibenzofurans and coplanar PCBs in foods) (Sep., 1999), Environmental Health Bureau, Ministry of Health and Welfare of Japan.

9) Daiokishinrui Ni Kakaru Dojyo Tyousa Sokutei Manual (Manual for investigation and determination of polychlorinated dibenzo- $p$-dioxins, dibenzofurans and coplanar PCBs in soils) (Jan., 2000), Water Quality Conservation Bureau, Ministry of Environment of Japan.

10) Van den Berg, M., Birnbaum, L., Bosveld, A. T. C., Brunström, B., Cook, P., Feeley, M., Giesy, J. P., Hanberg, A., Hasegawa, R., Kennedy, S. W., Kubiak, T., Larsen, J. C., Rolaf van Leeuwen, F.X., Djien Liem, A. K., Nolt, C., Peterson, R. E., Poellinger, L., Safe, S., Schrenk, D., Tillitt, D., Tysklind, M. M., Younes, M., W-rn, F., Zacharewski, T., Toxic equivalency factors (TEFs) for PCBs, PCDDs, PCDFs for humans and wildlife. Environ. Health Perspect., 106, 775-792 (1998).

11) Hülster, A., Müller, J. F., Marshner, H., Soil-plant transfer of polychlorinated dibenzo-p-dioxins and dibenzofurans to vegetables of the cucumber family (Cucurbitaceae). Environ. Sci. and Technol., 28, 1,110-1,115 (1994).

12) Neumann, G., Hulster, A., Römheld, V., PCDD/PCDFmobilizing compounds in root exudates of Zucchini. Organohalogen Comd., 41, 331-334 (1999).

13) Eun, Hee-Soo, Watanabe, E., Narita, I., Nakamura, K., Ishii, Y., Ueji, M., Comparisons of dioxin levels of cucumber varieties and cultivation periods. Organohalogen Comd., 66, 2,112-2,116 (2004).

14) Hülster, A., Marshner, H., Transfer of PCDD/PCDF from contaminated soils to food and fodder crop plants. Chemosphere, 27, 439-446 (1993).

15) Welsch-Pausch, K., Maclachlan, M. S., Umlauf, G., Determination of the principal pathways of polychlorinated dibenzo- $p$-dioxins and dibenzofurans to Lolium multiflorum (Welsh ray grass). Environ. Sci. and Technol., 29, 1,090-1,098 (1995).

16) Wagrowski, D. M., Hites, R., Partitioning of polychlorinated dibenzo-p-dioxins and dibenzofurans between the atmosphere and corn. Environ. Sci. and Technol., 32, 2,389-2,393 (1998).

17) Kuwahara, M., Uegaki, R., Seike, N., Possible pathways of dioxin accumulation to the above-ground portions of rice plants grown in contaminated soils. Organohalogen Comd., 58, 57-60 (2002).

18) Ogura, I., Masunaga, S., Nakanishi, J., Quantitative source identification of dioxin-like PCBs in Yokohama, Japan, by temperature dependence of their atmospheric concentrations. Environ. Sci. and Technol., 38, 3,2793,285 (2004). 
19) Takasuga, T., Inoue, T., Ishida, T., Ireland, P., Determination of the composition of the commercial PCBs: Kenechlor, Clophen, Arochlor, Chlofen and Sovol, by HRGCHRMS. Organohalogen Comd., 27, 391-396 (1996).

20) Sakai, S.-I., Hayakawa, K., Takatsuki, H., Kawakami, I., Dioxin-like PCBs released from waste incineration and their deposition flux. Environ. Sci. and Technol., 35, 3,601-3,607 (2001).

21) Kenkou Eiyou Jyohou Kenkyukai, ed. "Kokumin Eiyou No Jyoukyou, Heisei 10 Nen Kouseiroudou Shou Kokumin Eiyou Chousa Kekka (National Nutrition Survey in 1998, Japan)", Tokyo, Daiichi Shuppan, 2000. (ISBN 48041-0920-X)

22) Kenkou Eiyou Jyohou Kenkyukai ed. "Kokumin Eiyou No Jyoukyou, Heisei 11 Nen Kouseiroudou Shou Kokumin Eiyou Chousa Kekka (National Nutrition Survey in 1999, Japan)", Tokyo, Daiichi Shuppan, 2001. (ISBN 48041-0961-7)

23) Kenkou Eiyou Jyohou Kenkyukai ed. "Kokumin Eiyou No Jyoukyou, Heisei 12 Nen Kouseiroudou Shou Kokumin Eiyou Chousa Kekka (National Nutrition Survey in 2000, Japan)", Tokyo, Daiichi Shuppan, 2002. (ISBN 48041-0994-3)
24) Tsutsumi, T., Yanagi, T., Nakamura, M., Kono, Y., Uchibe, H., Iida, T., Hori, T., Nakagawa, R.; Tobiishi, K., Matsuda, R., Sasaki, K., Toyoda, M., Update of daily intake of PCDDs, PCDFs, and Coplanar PCBs from food in Japan. Chemosphere, 45, 1,129-1,137 (2001).

25) Harrison, N., Wearne, S., Gem, M. G. de M., Gleadle, A., Starting, J., Thorpe, S., Wright, C., Kelly, M., Robinson, C., White S., Hardy, D., Edinburgh, V., Time trends in human dietary exposure to PCDDS, PCDDS and PCBS in the UK. Chemosphere, 37, 1,657-1,670 (1998).

26) Rainer, M., Update of PCDD/PCDF-Intake from food in Germany. Chemosphere, 37, 1,687-1,698 (1998).

27) Schecter, A., Startin, J., Wright, C., Kelly, M., Päpke, O., Lis, A., Ball, M., Olson, J. R., Congener-specific levels of dioxins and dibenzofurans in U.S. food and estimated daily dioxin toxic equivalent intake. Environ. Health Perspect., 102, 962-966 (1994).

28) Toyoda, M., Uchibe, H., Yanagi, T., Kono, Y., Hori, T., Iida, T., Decreased daily intake of PCDDs, PCDFs and CoPCBs from foods in Japan from 1977 to 1998. Shokuhin Eiseigaku Zasshi (J. Food Hyg. Soc. Japan), 40, 494-499 (1999). 